\title{
Candida türlerinde biyofilm oluşumunun modifiye mikroplak ve modifiye XTT redüksiyon yöntemleri ile saptanması
}

Detection of biofilm formation in Candida species with modified microplate and modified XTT reduction methods

\author{
Uğur Tüzüner ${ }^{1} \quad$ Ramazan İnci ${ }^{2}$ \\ ${ }^{1}$ Necmettin Erbakan Üniversitesi Meram Tıp Fakültesi, Tıbbi Mikrobiyoloji Anabilim Dalı, Tıbbi Viroloji \\ Bilim Dalı, Konya, Türkiye \\ ${ }^{2}$ Ege Üniversitesi Tıp Fakültesi, Tıbbi Mikrobiyoloji Anabilim Dalı, İzmir, Türkiye
}

\section{Öz}

Amaç: İnvaziv girişimlerin artışı, geniş spektrumlu antibiyotiklerin kullanımı, immunsüpresif tedavilerin yaygınlaşması, kemik iliği baskılanması ve nötropeni gibi faktörler, ciddi fungal enfeksiyonların, özellikle Candida enfeksiyonlarının sıklığını arttırmaktadır. Bu artış kandidaların virülans faktörlerine dikkati çekmiştir. Biyofilm oluşturma kapasitesi önemli virülans faktörlerinden biridir. Çalışmamızda klinik örneklerden soyutlanan Candida türlerinde iki farklı yöntem ile biyofilm oluşumunu saptamayı amaçladık.

Gereç ve Yöntem: Çalışmada Ege Üniversitesi Tıp Fakültesi, Tıbbi Mikrobiyoloji Anabilim Dalı, Mikoloji Laboratuvarında 2012-2014 yıllarına ait çeşitli klinik örneklerden soyutlanmış ve stoklanmış 216 kandida izolatı kullanıldı. Biyofilm oluşumunu saptamak için modifiye mikroplak ve modifiye XTT redüksiyon yöntemleri, istatistiksel değerlendirmeler için ki-kare testi kullanıldı.

Bulgular: İncelenen kandidalarda modifiye mikroplak yöntemiyle \%19.4 ( $\mathrm{n=42})$, XTT redüksiyon yöntemiyle \%22.7 ( $n=49)$ biyofilm pozitifliği saptandı. Biyofilm pozitifliği mikroplak yöntemi ile; Candida albicans'ların \%12.5'inde ( $n=16)$, Albicans Dışı Candida'ların (ADC) \%29.5'inde ( $n=26)$, XTT redüksiyon yöntemi ile; Candida albicans'ların $\% 15.6$ 'sında $(n=20)$, ADC'lerin \%32.9'unda $(n=30)$ saptandı. Oranlar arasındaki fark istatistiksel olarak anlamlı bulundu (ki-kare=11.246; $\mathrm{p}=0.024)$. Biyofilm pozitifliği her iki yöntem ile en çok Candida tropicalis izolatlarında (13/30 ve 12/30) saptandı.

Sonuç: Çalışmamızda elde edilen verilere göre, modifiye XTT redüksiyon yönteminin biyofilm oluşumunu daha iyi saptadığı ve Candida tropicalis suşlarının daha fazla biyofilm oluşturduğu sonucuna vardık.

Anahtar Sözcükler: Candida, biyofilm, XTT, C.tropicalis.

\begin{abstract}
Aim: Increasing of invasive procedures, use of broad-spectrum antibiotics, widespread use of immunosuppressive therapy, bone marrow suppression and factors such as neutropenia is increasing the frequency of serious fungal infections; especially of Candida. This increase was noted to candida virulence factors. Biofilm forming capacity is an important virulence factor. In our study, we aimed to determine the biofilm formation of Candida species isolated from clinical specimens, by two different methods.

Materials and Methods: In this study 216 candida isolates which were identified and stocked from several clinical specimens which have been sent to Ege University, Medical Microbiology Department, Mycology Laboratory were used between 2012-2014 years. Modified microplate and modified XTT reduction methods have been used for determining the biofilm formation and chi-square test was used for statistical evaluations.

Results: The biofilm formation rate of Candida species was found to be $19.4 \%(n=42)$ with microplate method and $22.7 \%(n=49)$ with XTT reduction method. Biofilm formation was detected in $12.5 \%(n=16)$ of Candida albicans and 29.5\% ( $n=26$ ) of Non Albicans Candida (NAC) species with microplate method. However by using XTT reduction method biofilm formation detected in $15.6 \%(n=20)$ of Candida albicans and in \%32.9 ( $n=30)$ of NAC species. The difference between ratios was statistically relevant (chi-square $=11.246 ; p=0.024$ ). Biofilm formation detected most frequently in Candida tropicalis strains (13/30 and 12/30) by the two methods used.
\end{abstract}

\footnotetext{
Yazışma Adresi: Uğur Tüzüner

Necmettin Erbakan Üniversitesi Meram Tıp Fakültesi, Tıbbi Mikrobiyoloji Anabilim Dalı, Tıbbi Viroloji Bilim Dalı, Konya, Türkiye

Makalenin Geliş Tarihi: 06.10.2016 Kabul Tarihi: 20.12.2016
} 
Conclusion: On the basis of data obtained by the study, we concluded that modified XTT reduction method is identifying better the biofilm formation and Candida tropicalis strains formed more biofilm.

Keywords: Candida, biofilm, XTT, C.tropicalis.

\section{Giriş}

Candida türleri insan mikrobiyota üyesi mikroorganizmalardır. Bazı hazırlayıcı faktörlerin varlığında kandidozlara neden olurlar. Candida türleri, sistemik mikoz etkenleri arasında en sık görülenleridir. Çok sayıda olan Candida türlerinden ancak bazıları insanda enfeksiyon etkenidir. En sık görülen kandidoz etkeni Candida albicans'tır (1).

Tanı ve tedaviye yönelik yapılan invaziv girişimlerin artışı, geniş spektrumlu antibiyotiklerin kullanımı, organ nakilleri veya başka nedenlerle sık başvurulan güçlü immunsüpresif tedavilerin yaygınlaşması, malign hastalıklar nedeni ile verilen antikanser ilaçların neden olduğu kemik iliği baskılanması ve nötropeni gibi faktörler, ciddi fungal enfeksiyonların sıklığını arttırmaktadır (2). Bu artış araştırmacıların dikkatini kandidaların proteaz, esteraz, fosfolipaz ve biyofilm gibi virülans faktörlerine çekmiştir (3).

Kandidalar damar içi kateterler ve diğer medikal araçların yüzeyi ile temas ettiklerinde polisakkarit yapıda kompleks bir tabaka oluştururlar. Bu tabakaya biyofilm adı verilir. Biyofilmin en yeni tanımı ise; canlı veya cansız bir yüzeye yapışarak kendi ürettikleri organik bir ekzopolisakkarit matriks içine gömülü ve hareketsiz olarak birbirine, bir katı yüzeye veya bir ara yüzeye geri dönüşümsüz olarak tutunmuş halde yaşayan mikroorganizmaların oluşturduğu topluluktur (4).

Biyofilm oluşturma kapasitesi önemli virülans faktörlerinden biridir. $\mathrm{Bu}$ yüzden biyofilm oluşturan Candida türleri karşımıza; antifungal direnç, kronik enfeksiyon, yabancı cisim enfeksiyonları gibi klinisyenlerin karşılaşmak istemediği tablolarla çıkabilir. Bakterilerin ürettiği biyofilmin enfeksiyonlarla ilişkisine dair çok sayıda çalışma varken, mantarlarla ilgili bilgiler kısıtıdır. Bu nedenle kandidalardaki biyofilm yapısının anlaşılması, neden olduğu hastalıkların tedavisi ve izlemi için önem taşır (5).

Biyofilmlerin içindeki kandidaların antifungal ilaçlara daha dirençli olmasının birçok nedeni vardır. Bunlardan en önemlisi antifungal ilaçların biyofilm matriksine iyi penetre olamamasıdır. Ayrıca direnç gelişiminde biyofilm içindeki hücrelerin daha yavaş üremesinin ve biyofilme bağı hücrelerin yüzeyindeki değişikliklerin rol oynadığı düşünülmektedir $(6,7)$.

Biyofilm oluşumunu incelemek için kullanılan birçok yöntem vardır. Modifiye tüp adherans (8), mikroplak (9), Kongo kırmızılı beyin-kalp infüzyon agar $(9,10)$, glukozlu sıvı sabouraud agar ve glukozlu beyin-kalp infüzyon sıvisı (9), XTT redüksiyon (11), MTT tuzu ile görüntüleme (12), konfokal laser mikroskop ile görüntüleme (13), taramalı elektron mikroskop ile görüntüleme (14) gibi yöntemler tek başına ya da kombine şekilde kullanılmaktadır.

Hastalık etkeni olarak soyutlanan kandidaların biyofilm oluşturma özelliklerinin bilinmesi hastalığın izlenmesi ve tedavinin yönlendirilmesi yönünden önem taşır. Bu çalışmada amaç; klinik örneklerden soyutlanan Candida türlerinde modifiye mikroplak ve modifiye XTT redüksiyon yöntemleri ile biyofilm oluşumunu ve Candida türlerine göre biyofilm oluşturma derecelerini saptamaktır.

\section{Gereç ve Yöntem}

Ege Üniversitesi Tıp Fakültesi, Tıbbi Mikrobiyoloji Anabilim Dalı, Mikoloji Laboratuvarında çeşitli klinik örneklerden (farklı zaman aralıklarında farklı yöntemler kullanılarak); 1) Klasik yöntemler, 2) API 20C AUX, 3) VITEK ${ }^{\circledR}$ MS ile tür düzeyinde tanımlanmış, 2012-2014 yıllarına ait, boncuklu stok besiyerlerinde stoklanmış Candida izolatları kullanıldı. İzolatlar, her hastadan tek örnek alınarak stoklanmıştır. Stoklar tekrar üretilirken, boncuklar önce sıvı Sabouraud buyyona atıldı. 24 saat $35^{\circ} \mathrm{C}$ 'de inkübasyon sonrasında sıvı Sabouraud buyyonda üreme olanlardan Sabouraud Dekstroz Agar (SDA) besiyerine pasajları yapıldı. Üretilen mayaların çoğunluğu (177/216) kan ve kateter ucundan, geri kalanı ise (39/216) diğer klinik örneklerden (idrar, BOS, biyopsi ve solunum yolu örnekleri) soyutlanan izolatlardı. Çalışmaya alınan mayaların türlere göre dağılımı: $C$. albicans: 128/216 (\%59.3); C. tropicalis: 30/216 (\%13.9); C. glabrata: 29/216 (\%13.4); C. parapsilosis: $22 / 216$ (\%10.2); C. krusei: 7/216 (\%3.2) idi. Çalışmada kontrol köken olarak, C. albicans (ATCC 10231), C. parapsilosis (ATCC 22019), C. krusei (ATCC 6258) kullanıldı.

\section{Modifiye mikroplak yöntemi}

Kandida izolatları SDA besiyerine pasajlandıktan sonra 24 saat $35^{\circ} \mathrm{C}$ 'de inkübe edildi. Son konsantrasyonunda \%8 glukoz içeren Sabouraud dekstroz buyyon (SDB) hazırlandı. Her bir tüpe $2 \mathrm{ml}$ konulup otoklavda basınçlı buhar ile steril edildi. SDA'dan bir öze dolusu maya kolonisi alınarak \%8 glukozlu SDB içine inoküle edildi. $35^{\circ} \mathrm{C}$ 'de 24 saat inkübasyon sonrası etüvden çıkarılan tüpler 5 saniye vortekslendi. \%8 glukozlu SDB ile 1/40 oranında $\left(10^{7}\right.$ maya hücresi $/ \mathrm{ml}=\mathrm{Mc}$ Farland 4$)$ dilüe edildi. U tabanlı, 96 kuyucuklu, steril, polistiren plaklara; her örnek için üç kuyucuk olacak şekilde $200 \mu \mathrm{l}$ maya süspansiyonu pipetlendi. Her plakta pozitif kontrol amacıyla üç kuyucuğa standart kökenle aynı uygulamalarla hazırlanmış maya süspansiyonu, negatif kontrol amacıyla altı kuyucuğa boş besiyeri konuldu. 
Plaklar kapakları kapatılarak $35^{\circ} \mathrm{C}$ 'de 48 saat inkübe edildi. İnkübasyon sonrası kuyucuklar üç kere steril Phosphate Buffered Saline (PBS) ile yıkandı, ters çevrilerek kurutuldu.

Yöntemin bu kısmından sonrasında her iki yöntem için farklı basamaklar uygulanmıştır. Modifiye mikroplak yönteminde yıkanıp kurutulan plaklar \%1'lik kristal viyole ile 15 dakika boyandı. PBS ile yıkama işlemi tekrarlandıktan sonra fiksasyon için her bir kuyucuğa $200 \mu \mathrm{l}$ etanol-aseton (80:20 vol/vol) eklendi. ELISA Mikroplak okuyucu cihazda (Organon Teknika Mikrowell System $^{\circledR}$ ) $620 \mathrm{~nm}$ dalga boyunda kuyucukların optik dansiteleri saptandı.

Değerlendirmede optik dansite sonucuna göre kantitatif skala kullanıldı. İzolatların her biri için çalışılan üç kuyucuğun OD ortalaması alındı. Çıkan değer $\leq 1$ ise: negatif; > 1 pozitif olarak değerlendirildi (15).

\section{Modifiye XTT redüksiyon yöntemi}

$\mathrm{Bu}$ yöntemde ortak kısım sonrasında XTT (2,3-Bis(2methoxy-4-nitro-5-sulfophenyl)-2H-tetrazolium-5-carboxanilid) $\left(\right.$ Cayman $^{\circledR}$ ) son konsantrasyonu $1 \mathrm{mg} / \mathrm{mL}$ olacak şekilde PBS içinde çözündürüldü. Hazırlanan solüsyon $0.22 \mu \mathrm{m}$ 'lik filtreden geçirilerek sterilize edildi, alikotlanıp çalışma yapılana kadar ışık görmeyecek şekilde $80^{\circ} \mathrm{C}$ 'de saklandı. Menadione (Sigma Aldrich $\left.{ }^{\circledR}\right)(0.4$ $\mathrm{mM} / a$ seton içinde hazırlanmış) solüsyonu da her çalışmadan hemen önce hazırlandı ve $0.22 \mu \mathrm{m}$ 'lik filtreden geçirilip sterilize edilerek çalışmaya alındı. Yıkanmış ve kurumuş kuyucukların her birine, XTT ve Menadione yirmiye bir oranında olacak şekilde; $79 \mu \mathrm{L}$ PBS, $20 \mu \mathrm{L}$ XTT ve $1 \mu \mathrm{L}$ Menadione solüsyonu aktarıldı. Plaklar $35^{\circ} \mathrm{C}$ 'de karanlıkta 3 saat inkübe edildikten sonra, ELISA Mikroplak okuyucu cihazda (Organon Teknika Mikrowell System $\left.{ }^{\circledR}\right) 492$ nm dalga boyunda kuyucukların optik dansiteleri saptandı.

Değerlendirmede optik dansite sonucuna göre kantitatif skala kullanıldı. İzolatların her biri için çalışılan üç kuyucuğun OD ortalaması alındı. Çıkan değer $\leq 0.1$ ise negatif; $>0.1$ ise pozitif olarak değerlendirildi (16).

Çalışmadan elde edilen sonuçlar Statistical Package for the Social Sciences (SPSS ${ }^{\circledR} 16.0$ for Windows) veri tabanına işlendi. Oranlar arasındaki farkların istatistiksel açıdan değerlendirilmesi için Ki-kare testi kullanıldı.

\section{Bulgular}

Yöntemlere göre kandidaların biyofilm oluşturma özellikleri incelendiğinde modifiye mikroplak yöntemiyle \%19.4'nün (n=42), XTT redüksiyon yöntemiyle \%22.7'sinin $(n=49)$ biyofilm oluşturduğu saptandı. Mikroplak yöntemiyle; C. albicans'ların \%12.5'inin $(\mathrm{n}=16), \quad A D C^{\prime}$ ların \%29.5'inin $\quad(\mathrm{n}=26)$ biyofilm oluşturduğu, XTT redüksiyon yöntemiyle; $C$. albicans'ların \%15.6'sının ( $\mathrm{n}=20)$, ADCların \%32.9'unun $(n=30)$ biyofilm oluşturduğu görüldü (Tablo-1). Biyofilm oluşturma oranları açısından, XTT redüksiyon ve mikroplak yöntemleri arasındaki fark, ayrıca $C$. albicans ve $A D C$ 'lar arasındaki fark istatistiksel olarak anlamlı bulundu $(x 2=11.246 ; p=0.024)$. Her iki yöntemle de en fazla biyofilm oluşturma oranı $A D C$ lardan olan $C$. tropicalis'e (13/30 ve 12/30) aitti.

Tablo-1. Biyofilm Oluşturan Candida'ların Yöntemlere Göre Dağılımı.

\begin{tabular}{lcc}
\hline & \multicolumn{2}{c}{$\begin{array}{c}\text { Biyofilm deneylerinde uygulanan } \\
\text { Modifiye Yöntemler }\end{array}$} \\
\cline { 2 - 3 } Candida türleri & Mikroplak (\%) & XTT Redüksiyon (\%) \\
\hline C. albicans & $16 / 128(12.5)$ & $20 / 128(15.6)$ \\
ADC'lar & $26 / 88(29.5)$ & $29 / 88(32.9)$ \\
\hline
\end{tabular}

$x_{2}=11.246 ; p=0.024 ; A D C$ : Albicans dışı Candida

\section{Tartışma}

Kandidalar fırsatçı mantar enfeksiyonları etkenlerindendir. Sistemik ve yüzeyel kandidozlar son yıllarda artış göstermiştir. Kandidozlardan, aynı zamanda mikrobiyota üyesi de olan $C$. albicans sorumlu olarak sıklıkla soyutlanırken, son yıllarda $A D C$ türlerine bağlı enfeksiyonlar sık görülmektedir (17). Kandidozların artmasında konağa bağlı faktörlerin (bağışık engellilik, steroid ve antibiyotik tedavisi, vb.) yanısıra, etkenlere bağlı virülans faktörleri de çok önemlidir (18).

Yaptığımız çalışmada özellikle; klinik kökenli Candida türlerinde biyofilm oluşumunu ve derecesini saptamak, biyofilm oluşumunu en hızlı, objektif ve ucuz yöntemle gösterebilmek hedeflendi. Candida'larla yapılan biyofilm çalışmaları çoğu kez klinik örneklerden soyutlanan izolatlarla yapılmıştır (14). Çalışmamızda da kan kültürlerinden ve diğer klinik örneklerden soyutlanan Candida izolatlarında biyofilm oluşumu araştırılmıştır. Uygulaması kolay, değerlendirmesi objektif ve ucuz bir yöntem olması nedeniyle modifiye mikroplak ve modifiye XTT redüksiyon biyofilm araştırma yöntemleri seçilmiştir. $\mathrm{Bu}$ iki yöntemin kullanıldığı çeşitli çalışmalar da vardır (19-21). Biyofilm konusunda yapılan çalışmalarda altın standart yöntem henüz netleşmemiştir. Ancak, altın standart olarak uygulanabilecek yöntemlerden bahsedilmektedir. XTT redüksiyon yöntemi de bunlardan biridir. Ülkemizde yapılan bir çalışmada mikroplakta XTT redüksiyon yönteminden, uygulama kolaylığı, iki saat gibi kısa bir sürede sonuç vermesi, sonuçların objektif olarak değerlendirilmesi ve tekrarlanabilir olması nedeniyle biyofilm varlığının saptanmasında uygun bir yöntem olarak bahsedilmiştir. Ancak, maliyetinin benzer yöntemlere göre daha yüksek olduğunun altı çizilmiştir (22).

HIV enfeksiyonu olan hastaların ağız sürüntülerinden soyutlanan kandidalarla, XTT redüksiyon ve mikroplak yöntemleri kullanılarak yapılan bir çalışmada kökenlerde mikroplak ile saptanan biyofilm oluşum oranının XTT redüksiyon yöntemi ile saptanandan daha fazla olduğu, ancak bu sonuca rağmen XTT redüksiyon yönteminin, 
mikroplak yöntemine göre daha güvenilir olduğu vurgulanmıştır (23).

Altta yatan hastalıkları farklı olan ve ayrıca HIV enfeksiyonu da olan kandidemili hastalardan soyutlanan 126 farklı Candida izolatında; mikroplak ve XTT redüksiyon yöntemi ile biyofilm oluşumunun ve virülansla ilişkilerinin gösterildiği çalışmada $C$. albicans izolatlarında biyofilm oluşumu daha fazla saptanmıştır. Biyofilm oluşumu görülen izolatların çoğunun antifungallere dirençli olduğu; özellikle persistan hastalıklarda biyofilm yapımının kandidalar için önemli bir virülans faktörü olduğu vurgulanmıştır (24).

Yapılan birçok çalışmada $A D C$ izolatlarında biyofilm oluşumunun $C$. albicans izolatlarına göre daha fazla olduğu belirtilmiştir. Bu izolatlar arasında en çok biyofilm pozitifliği $C$. tropicalis türlerinde saptanmıştır $(13,14,25$, 26).

Biyofilm oluşturan izolatlarla enfekte olanlarda hastanede yatış süresi, toplam tedavi ücreti ve mortalite anlamlı derecede yüksek bulunmuştur. Ayrıca bu hastaların antifungal tedavide biyofilmlere daha yüksek etkili antifungallere intiyaç duyduğu da belirtilmiştir (13). Tüm bu çalışmalarda olduğu gibi çalışmamızda da biyofilm oluşumu en fazla olan Candida türü $C$. tropicalis olarak saptanmıştır.

Türkiye'de yapılan çalışmaların çoğunluğu modifiye tüp adherans yöntemin kullanıldığı çalışmalardır (27-29). Bunların çoğunda Candida türlerindeki biyofilm oluşumlarına bakıldığında $A D C$ izolatlarında biyofilm pozitifliğinin $C$. albicans izolatlarına göre belirgin şekilde daha fazla olduğunu saptanmıştır $(27,28)$.
Klinik örneklerden soyutlanan 116 Candida izolatında modifiye mikroplak yöntemi ile biyofilm oluşumunun incelendiği çalışmada, izolatların 33'ünün (\%28) biyofilm oluşturduğu ayrıca kan kültür örneklerinden soyutlanan izolatlarda biyofilm oluşturma oranının daha yüksek olduğu saptanmıştır (\%33). ADC izolatlarında (\%41) biyofilm oluşturma oranı $C$. albicans izolatlarına göre (\%23) daha yüksek bulunmuştur (30). Çalışmamızda da kan kültürlerinden soyutlanan $A D C$ türlerinde daha çok biyofilm pozitifliği saptanmıştır. Bu sonucu çalışmamızda kan kültürlerinden soyutlanan izolatların çoğunlukta olmasına bağlayabiliriz. Yaptığımız çalışmayla uyumlu olarak bu çalışmada da modifiye mikroplak yöntemiyle en fazla biyofilm oluşumu $C$. tropicalis izolatlarında saptanmıştır.

\section{Sonuç}

Kandidemi ve katetere bağı enfeksiyonlarda sıklıkla Candida türleri soyutlanmaktadır. Candida enfeksiyonlarının patogenezinde virülans faktörlerinden biri olan biyofilmin önemli olduğu yapılan çalışmalarda belirtilmiştir. Çalışmamız sonunda, Modifiye XTT redüksiyon yönteminin biyofilm oluşumunu daha iyi saptadığı ve $A D C$ türlerinden $C$. tropicalis suşlarının daha fazla biyofilm oluşturduğu kanaatine vardık. Bu sonuç benzer çalışmaların sonuçları ile uyumludur. Ayrıca biyofilm oluşumunu saptamak amacıyla kullanılan modifiye mikroplak ve modifiye XTT redüksiyon yöntemleri, uygulaması kolay, değerlendirmesi objektif ve ucuz yöntemlerdir.

\section{Kaynaklar}

1. Tümbay E. Candida türleri. In: Ustaçelebi Ş (ed). Temel ve Klinik Mikrobiyoloji, Ankara: Güneş Kitabevi; 1999:1081-86.

2. Arens MQ, Swierkosz EM. Taxonomy and classification of fungi, In: Murray PR, Baron EJ, Jorgensen JH, Landry ML, Pfaller MA (ed), Manual of Clinical Microbiology Vol 2. 9th ed, Washington DC: ASM Press: 2007:1721-27.

3. Çerikcioğlu N, Sancak B. Mantarların genel özellikleri ve tanı yöntemleri. In: Willke AT, Söyletir G, Doğanay M (eds). Enfeksiyon Hastalıkları ve Mikrobiyolojisi, İstanbul: Nobel Tıp Kitabevleri; 2008:2391.

4. Donlan RM, Costerton JW. Biofilms: Survival mechanisms of clinically relevant microorganisms. Clin Microbiol Rev 2002;15(2):167-93.

5. Kojic EM, Darouiche RO. Candida infections of medical devices. Clin Microbiol Rev 2004;17(2):255-67.

6. Hawser SP, Douglas LJ. Resistance of Candida albicans biofilms to antifungal agents in vitro. Antimicrob Agents Chemother 1995;39(9):2128-31.

7. Jabra-Rizk MA, Falkler WA, Meiller TF. Fungal biofilms and drug resistance. Emerg Infect Dis 2004;10(1):14-9.

8. Pfaller M, Davenport D, Bale M, et al. Development of the quantitative microtest for slime production by coagulase-negative staphylococci. Eur J Clin Microbiol Infect Dis 1988;7(1):30-3.

9. Hilmioğlu S, İlkit M, Çavuşoğlu C, Aydemir Ş, Tümbay E. Candida izolatlarında slaym (slime) üretiminin üç ayrı yöntemle gösterilmesi ve slaym üretiminin kristal viyole reaksiyonu ile ilişkisi. İnfeks Derg 1999;13(2):183-6.

10. Arslan U, Fındık D. Klinik örneklerden izole edilen Candida albicans türü maya mantarlarında virülans faktörlerinin (proteinaz, slime ve fosfolipaz) in-vitro araştırılması. İnfeks Derg 2003;17(4):471-81.

11. Roehm NW, Rodgers GH, Hatfield SM, et al. An improved colorimetric assay for cell proliferation and viability utilizing the tetrazolium salt XTT. J Immunol Met 1991;142(2):257-65.

12. Krom BP, Cohen JB, Feser GEM, et al. Optimized candidal biofilm microtiter assay. J Microbiol Met 2007;68(2):421-3.

13. Silva WJ, Gonçalves LM, Seneviratne J, et al. Exopolysaccharide matrix of developed Candida albicans biofilms after exposure to antifungal agents. Braz Dent J 2012;23(6):716-22. 
14. Pannanusorn S, Fernandez V, Römling U. Prevalence of biofilm formation in clinical isolates of Candida species causing bloodstream infection. Mycoses 2013;56(3):264-72.

15. Toledo-Arana A, Valle J, Solano C, et al. The enterococcal surface protein, Esp, is involved in Enterococcus faecalis biofilm formation. Appl Environ Microbiol 2001;67(10):4538-45.

16. Thein ZM, Samaranayake YH, Samaranayake LP. In-vitro biofilm formation of Candida albicans and non-Albicans Candida species under dynamic and anaerobic conditions. Arch Oral Biol 2007;52(8):761-7.

17. Kayabaş Ü, Aygen B. Fungal sepsis. Hast İnfeks Derg 2009;13(2):129-35.

18. Yıldıım M, Mumcuoğlu I, Kurşun Ş, et al. Enfeksiyon etkeni olarak izole edilen Candida albicans ve ADC suşlarındaki bazı virülans faktörlerinin karşılaştırılması. Türk Mikrobiyol Cem Derg 2009;39(1):62-8.

19. Li X, Yan Z, Xu J. Quantitative variation of biofilms among strains in natural populations of Candida albicans. Microbiology 2003;149(Pt 2):353-62

20. Peeters E, Nelis HJ, Coenye T. Comparison of multiple methods for quantification of microbial biofilms grown in microtiter plates. J Microbiol Meth 2008;72(2):157-65.

21. Peters BM, Ward RM, Rane HS, et al. Efficacy of ethanol against Candida albicans and Staphylococcus aureus polymicrobial biofilms. Antimicrob Agents Chemother 2013;57(1):74-82.

22. Aslan H, Gülmez D. Investigation of the correlation between biofilm forming ability of urinary Candida isolates with the use of urinary catheters and change of antifungal susceptibility in the presence of biofilm. Mikrobiyol Bul 2016;50(2):256-65.

23. Jin Y, Yip HK, Samaranayake YH, Yau JY, Samaranayake LP. Biofilm-forming ability of Candida albicans is unlikely to contribute to high levels of oral yeast carriage in cases of human immunodeficiency virus infection. J Clin Microbiol 2003;41(7):2961-7.

24. Hasan F, Xess I, Wang X, et al. Biofilm formation in clinical Candida isolates and its association with virulence. Microbes and Infect 2009;11(8-9):753-61.

25. Tumbarello M, Posteraro B, Trecarichi EM, et al. Biofilm production by Candida species and inadequate antifungal therapy as predictors of mortality for patients with candidemia. J Clin Microbiol 2007;45(6):1843-50.

26. Ferreira AV, Prado CG, Carvalho RR, et al. Candida albicans and non-C. albicans Candida species: Comparison of biofilm production and metabolic activity in biofilms, and putative virulence properties of isolates from hospital environments and infections. Mycopathologia 2013;175(3-4):265-72.

27. Satılmış ÖK, Akkaya Y, Ergin Ç, Kaleli İ. Çeşitli klinik örneklerden izole edilen Candida spp izolatlarında slime faktör üretimi. Pam Tıp Derg 2011;4(1):25-9.

28. Yakupoğulları Y, Toraman ZA. Çeşitli klinik örneklerden soyutlanan Candida izolatlarında slime faktörü üretiminin araştırıması. Türk Mikrobiyol Cem Derg 2004;34(3):178-81.

29. Ozkan S, Kaynak F, Kalkanci A, Abbasoglu U, Kustimur S. Slime production and proteinase activity of Candida species isolated from blood samples and the comparison of these activities with minimum inhibitory concentration values of antifungal agents. Mem Inst Oswaldo Cruz 2005;100(3):319-24.

30. Demirbilek M, Timurkaynak F, Can F, Azap Ö, Arslan H. Hastane Kaynaklı Candida Türlerinde Biyofilm Oluşumu ve Antifungal Duyarlılık Paternleri. Mikrobiol Bul 2007;41(2):261-9. 